\title{
UNSUR BAHASA KIASAN METAFORA DALAM SAMPI IBAN
}

\author{
Elements of the Figurative Language of Metaphor in Sampi Iban \\ Saripah Banseng \\ bsaripah@gmail.com \\ Rosline Sandai \\ rosline@fbk.upsi.edu.my \\ Universiti Pendidikan Sultan Idris
}

\begin{abstract}
ABSTRAK
Sampi atau mantera merupakan puisi tradisional kaum Iban dalam kategori invokasi yang berfungsi sebagai permohonan doa untuk mendapatkan pertolongan atau perlindungan. Kata-kata dalam sampi yang dilafazkan kepada Petara (Dewa-dewi) digayakan dengan bahasa kiasan metafora menambahkan lagi keindahan seni berpuisi dikalangan masyarakat Iban. Kajian ini bertujuan untuk menganalisis unsur-unsur yang membentuk bahasa kiasan metafora dalam mantera perhumaan (sampi umai) masyarakat Iban. Berasaskan pendekatan secara kualitatif, kaedah deskriptif digunakan untuk mengkaji dua buah sampi perhumaan yang diambil daripada buku Sampi Enggau Biau. Analisis kandungan digunakan untuk menganalisis bahasa kiasan yang terdapat dalam sampi. Dapatan kajian menunjukkan bahasa kiasan sampi terdiri daripada unsur alam seperti tumbuhan, haiwan, dan manusia, yang disesuaikan dengan unsur bukan alam yang dicipta dan menjadi budaya dalam kehidupan mereka. Unsur-unsur ini digunakan untuk menyatakan warisan tradisi, merendahkan diri, persembahan sajian (piring), kehebatan perwira, kecantikan wanita dan hasil padi. Implikasi kajian ini menunjukkan penggunaan unsur alam dan bukan alam dalam bahasa kiasan metafora menambahkan pengetahuan pengamal tentang kemahiran berbahasa.
\end{abstract}

Kata kunci Bahasa kiasan; metafora; sampi perhumaan; alam; bukan alam

\begin{abstract}
Sampi or mantra is a traditional poem of Iban in the category of invocation which functioned as a prayer request for help or protection. The words which uttered in sampi to Petara (Goddess) styled with the figurative language of metaphor enhances the beauty of poetry among the Iban community. This study aims to analyse the elements that formed the figurative languages of metaphor in the paddy cultivation prayers (sampi umai). Based on qualitative approach, descriptive method was used to examine two paddy cultivation prayers which were taken from a book entitled SampiEnggauBiau. Content analysis was used to analyse the figurative language in the sampi. Results showed the figurative language of metaphor in the Iban sampi consist of nature such as plants, animals and human which are then adjusted to the non-nature elements which were made and became a culture in their lives. These elements were used to symbolise the inheritance of tradition, humbleness, offering presentation (piring), the greatness of the warrior, the beauty of woman, crowds and the harvest of paddy. The implications of this study show that the use of nature and non-nature elements in the metaphor enhances practitioner's knowledge about the language.
\end{abstract}

Keywords Figurative language; metaphor; cultivation prayers; nature; non-nature

\section{PENGENALAN}

Sampi atau mantera merupakan puisi tradisional kaum Iban dalam kategori Invokasi. Invokasi merupakan permohonan, biasanya kepada Tuhan, untuk mendapatkan pertolongan atau perlindungan (Tana Showren, 2014). Dalam tradisi lisan, Invokasi ialah amalan untuk memohon sesuatu atau permintaan dalam bentuk doa dan mantera.Masyarakat Iban mengamalkan sampi melalui permohonan doa kepada Petara (dewadewi), Bunsu-bunsuAntuManah (entiti atau spirit yang baik) dan roh saudara mara atau nenek moyang (Robert Menua Saleh dan Janang Ensiring, 2001). 
Sampi sering kali diamalkan semasa aktiviti perhumaan yang merupakan pekerjaan utama masyarakat Iban suatu ketika dahulu (Lockard dan Saunders, 1992). Sampi perhumaan dilafazkan sesuai dengan kitaran atau proses penanaman padi bukit, iaitu menebang, membersihkan kawasan, membakar dan menanam.

Ungkapan yang dilafazkan dalam sampi mempunyai ciri-ciri yang hampir sama ekoran kepercayaan mereka terhadap para Dewa-dewi (Petara), entiti dan roh. Selain itu, tujuan mereka memohon doa ialah untuk meminta keberkatan dan kemakmuran dalam hidup masing-masing. Kata-kata dalam sampi yang dilafazkanoleh pengamal berbeza mengikut daerah dan tempat masing-masing. Namun demikian bahasa kiasan yang digunakan dalam sampi hampir sama kerana faktor alam dan budaya dalam kehidupan masyarakat Iban adalah sama. Oleh hal demikian, kajian ini menganalisis unsur-unsur dalam bahasa kiasan metafora yang ada dalam sampi.

\section{PERNYATAAN MASALAH}

Pengamal yang melafazkan sampi dikenali sebagai lemambang menunjukkan kemahirannya melalui penyusunan serta penggunaan ungkapan yang dilafazkan secara spontan dalam binaan sampi. Sehubungan itu, penggunaan bahasa kiasan metafora memainkan peranan dalam membentuk corak puisi tradisional tersebut. Kekurangan penekanan daripada orang tua yang arif dalam sampi ini menjadikan ramai generasi muda hari ini mengalami kesukaran dalam memahami bahasa kiasan metaforayang terdapat dalam sampi. Keadaan menjadi semakin kritikal apabila populasi orang tua yang arif dan berpengalaman juga semakin berkurangan (Sandai, 2011) sekaligus menambahkan kesukaran untuk mendapat panduan dalam penyusunan bahasa dan aturan sampi tersebut. Kesukaran memahami tradisi lisan menjadikan golongan muda kurang meminati kebudayaan sendiri.Sehubungan dengan itu, kajian ini dilakukan untuk membantu golongan generasi muda memahami dan meneliti unsur-unsur yang membentuk bahasa kiasan metafora dalam sampi.

\section{OBJEKTIF KAJIAN}

Objektif yang mendasari kajian ini ialah menganalisis unsur-unsur yang membentuk bahasa kiasan metafora dalam sampi. Unsur-unsur tersebut ialah unsur alam dan unsur bukan alam yang terdiri daripada benda atau peralatan yang dicipta serta digunakan dalam masyarakat Iban.

\section{TINJAUAN LITERATUR}

Masyarakat tradisional sangat kreatif menggunakan unsur sekeliling dalam menyampaikan maksud tertentu. Penggunaan alam untuk menyatakan maksud tersirat bukan sesuatu yang baru. Menurut kajian Ding Choo Ming (2009), penggunaan imej alam ini menunjukkan hubungan yang rapat dengan alam semula jadi dalam jiwa, rasa, hati dan raga sesuatu masyarakat. Binaan maksud tersirat yang menonjolkan tema manusia dan alam semula jadi memperkayakan budaya serta kualiti hidup sesuatu masyarakat (Ding Choo Ming, 2009). Penciptaan maksud tersirat adalah berdasarkan fenomena sebenar dalam kehidupan masyarakat (Zaitul Azma Zainon dan Ahmad Fuad Mat Hassan, 2011).

Goh Sang Seong (2010)pula berpendapat kedudukan geografi turut mempengaruhi pembentukan bahasa kiasan penduduk. Kajian tersebut mendapati haiwan liar dijadikan sebagai lambang dalam bahasa Mandarin dan bahasa Melayu. Antaranya ialah harimau, kera, anjing, ketam, gajah, kambing, serigala, tikus dan kucing. Haiwan liar seperti harimau dilambangkan sebagai tanda bahaya dan tidak mengenang budi, manakala kera melambangkan kepandaian dan kemahiran. Anjing dilambangkan sebagai orang yang tidak mengenang budi, ketam melambangkan orang yang tidak menunjukkan teladan, gajah sebagai lambang kepada kuasa besar, kambing dilambangkan sebagai orang yang lemah lembut dan jinak. Serigala melambangkan keganasan dan kezaliman manakala kucing melambangkan ketua atau pihak yang lebih dominan dalam sesuatu kumpulan. Selain itu, tikus melambangkan orang bawahan.

Selain penggunaan haiwan, penggunaan unsur tumbuhan juga digunakan untuk membentuk maksud tersirat (Resa Sindi Harja, 2014). Antara tumbuhan yang digunakan rotan, akar, batang, aur dan sekam. Penggunaan unsur ini digunakan untuk menyatakan sikap manusia atau budaya sesuatu masyarakat. Resa Sindi Harja (2014) juga menyatakan penggunaan unsur tumbuhan ini kemudian 
disesuaikan dengan benda bukan alam untuk menyerlahkan keindahan bahasa kiasan tersebut. Berdasarkan kajian yang telah dijalankan, jelaslah bahawa penggunaan bahasa kiasan untuk menyampaikan maksud tertentu memang tidak dapat dipisahkan dalam sesuatu masyarakat di dunia ini.

Persekitaran kehidupan sesuatu masyarakat yang begitu rapat dengan alam sekitar membolehkan mereka membentuk perlambangan-perlambangan yang sesuai dalam membina ujaran lembut tetapi bermakna. Kemampuan berfikir secara kreatif juga dapat ditonjolkan dengan menyimpang dari pola yang sama dan berfikir di luar rutin yang biasa (Mohd. Azhar Abdul Hamid, 2006). Keadaan ini sedikit sebanyak mempengaruhi keindahan bahasa yang digunakan dalam penyampaian puisi tradisional. Kemahiran menggunakan bahasa juga mempengaruhi pengucapan dalam struktur sampi.

\section{METODOLOGI}

Kajian ini menggunakan pendekatan kualitatif secara deskriptif. Kaedah deskriptif digunakan untuk menerangkan, menganalisis dan menjelaskan sesuatu melalui teknik pelbagai, tinjauan, temubual dan penelitian (Fraenkel dan Wallen, 1993). Melalui analisis dan penelitian teks sampi bahasa kiasan dapat dihuraikan dengan bebas dan terbuka tentang makna dan fungsinya dalam amalan perhumaan masyarakat Iban di Sarawak.

Bahasa kiasan metafora dalam sampi dianalisis menggunakan teori linguistik kognitif (Lakoff dan Johnson, 1980). Berdasarkan teori tersebut, bahasa merupakan suatu lambang, sehingga setiap bentuk bahasa dianggap mempunyai makna serta mempunyai unsur yang membentuknya (Lakoff dan Johnson, 1980). Berdasarkan teori ini, unsur alam dan bukan alam merupakan lambang yang digunakan dalam pembentukan bahasa kiasan metaforasampi. Dengan erti kata lain, ranah sumber (source domain) digunakan manusia untuk memahami konsep abstrak dalam ranah sasaran (target domain) (Lakoff dan Johnson, 1980). Konteks alam dan budaya yang mendasari kewujudan bahasa kiasan metafora menjadikan teks data mudah dikenal pasti.

\section{DAPATAN KAJIAN}

Kajian ini mendapati bahawa kebanyakan bahasa kiasan dalam sampi adalah berteraskan unsur alam dan bukan alam yang menjadi budaya dalam masyarakat Iban. Untuk menyatakan maksud sebenar dalam sampi, alam dan budaya ini disesuaikan dengan unsur bukan alam, iaitu benda ciptaan manusia seperti peralatan atau pakaian yang digunakan dalam kehidupan seharian masyarakat Iban. Unsur alam dan bukan alam tersebut digunakan untuk menyatakan warisan tradisi, merendahkan diri, persembahan sajian (piring), kehebatan perwira, kecantikan wanita dan hasil padi. Berikut merupakan penerangan unsur bagi setiap bahasa kiasan yang dikenal pasti.

\section{Warisan Tradisi}

Sebelum membuat permohonan, pengamal membuat pendakwaan diri dengan menyatakan mereka mewarisi amalan sampi mengikut adat secara tradisi yang diturunkan dari nenek moyang zamanberzaman.Contoh bahasa kiasan yang digunakan ialah 'laban aku tu baka ijuk tampung penduk, baka rutan tampung danan, baka wi tampung tali (kerana aku seperti enau disambung penduk, seperti rotan disambung danan, seperti rotan disambung tali). Rutan (rotan), danan (tali rotan), danwi (rotan) merupakan tumbuhan menjalar yang boleh digunakan untuk membuat tali (Leornad, Sutlive dan Edmund, 2011). Ijuk merupakan sejenis pokok kabung atau palma yang pelepahnya boleh dibuat tali dan penyapu (Phang Wien Ho et al., 1983) manakala penduk ialah sejenis pokok yang menghasilkan bunga berbau busuk dan kulitnya boleh dibuat tali (Turner, 2010). Kelima-lima tumbuhan ini mempunyai satu persamaan iaitu boleh digunakan untuk membuat tali. Oleh hal yang demikian, kaum Iban melambangkan tumbuhan ini sebagai warisan tradisi dalam amalan sampi.

\section{Merendahkan Diri}

Pengamal membuat pengakuan dengan kerendahan hati di hadapan Petara (Dewa-dewi). Contoh bahasa kiasan yang digunakan sebagai lambang merendahkan diri ialah 'lela baka ambun belayar midang' (lesap 
seperti embun belayar tidak diketahui belayar) yang membawa maksud kehebatan Iban sangat rendah jika dibandingkan dengan kekuasaan Petara (Dewa-dewi). Mereka mengumpamakan diri mereka seperti embun yang pasti jatuh dan hilang. Unsur alam yang digunakan dalam pernyataan maksud tersirat ini ialah embun.

\section{Persembahan Sajian (Piring)}

Bahasa kiasan metafora juga digunakan untuk menyampaikan persembahan sajian (piring) yang disediakan semasa mengamalkan sampi. Suku kaum Iban memberi yang terbaik dalam persembahan sajian sehingga mengibaratkan persembahan tersebut 'baka tangkup bunga kejumpang' (ibarat kelopak bunga kejumpang)dan 'baka bulan perenama rumpang'(laksana bulan purnama). Bahasa kiasan metafora tersebut melambangkan betapa menariknya persembahan sajian yang mereka sediakan untuk Petara (Dewa-dewi). Unsur alam yang digunakan ialah kelopak bunga dan bulan purnama.

\section{Kehebatan Perwira}

Kehebatan lelaki yang dipuji oleh pengamal merupakan perwira suku kaum Iban yang diseru dalam sampi. Kehebatan perwira ini digambarkan seperti 'Rajang nunggang baka tugang langgai manuk, Rajang nunggang baka tugang manuk jelayan, Bungkung ngembung renjung-renjung baka serumbung kelita tuan' (keperwiraannya laksana ekor ayam jantan yang berjurai panjang, keperkasaannya laksana ekor ayam jantan yang bercorak menarik, kejantanannya menjulang tinggi seperti serombong pelita tuan). Kehebatan perwira suku kaum Iban diibaratkan seperti ayam jantan untuk menyerlahkan kejantanan atau kelelakian mereka.

\section{Kecantikan Wanita}

Kaum Iban turut menggunakan unsur alam dan budaya untuk menyatakan kecantikan wanita. Wanita yang dimaksudkan kebanyakan isteri para Dewa, isteri para entiti dan isteri Burung Kihanatan. Kecantikan wanita dilihat dari segi fizikal yakni melalui keelokan budi pekerti melalui cara duduk yang diibaratkan seperti cara duduk bini tuan (isteri orang terhormat). Wanita tersebut turut dipuji melalui ikatan sanggul di rambut contohnya 'baka pulas idas tekuyung kaban' (laksana lingkaran sekawan siput) yang digunakan untuk memuji kecantikan isteri burung Embuas (Burung Pekaka Riang Rimba). Selain itu, kecantikan wanita juga dilihat melalui cara dia berjalan yang diibaratkan seperti tanggi (topi) yang dibuai-buai ditiup angin contohnya 'kayak-kayak baka cherindak tanggi dianyam' (lemah gemalai seperti lebarnya anyaman topi). Kecantikan wanita ini dikiaskan menggunakan unsur alam seperti haiwan dan manusia serta unsur bukan alam, iaitu topi.

\section{Kehadiran Orang Ramai}

Selain itu, unsur alam dan budaya turut digunakan untuk melambangkan kehadiran orang ramai. Unsur alam yang digunakan ialah beluh (ikan sungai) dan tungkul pisang (jantung pisang). Bahasa kiasan metafora tersebut ialah 'Enti baka tu bedau mayuh kitai, baka beluh kambuh enseluan, bedau banyak kitai, baka kerupak tungkul pisang' (kita masih belum ramai seperti beluh mengelirukan enseluang, kita masih belum ramai seperti kelopak jantung pisang). Orang yang ramai diumpamakan seperti ikan beluhsejenis ikan air tawar yang bersisik mengelirukan ikan enseluang yang juga hampir sama dengan ikan beluh. Kehadiran orang ramai turut diumpamakan seperti kelopak jantung pisang. Unsur alam yang digunakan dalam bahasa kiasan metafora ini ialah ikan dan jantung pisang.

\section{Hasil Padi}

Hasil padi yang lumayan juga turut dilafazkan dalam bentuk tersirat. Bahasa kiasan metafora yang digunakan untuk menggambarkan hasil padi adalah 'Nya baru padi kita tak sebaka nadai nawang, Kita ngingatka semaya enggau Bintang Banyak, Tumbuh di awak langit burak, Baka lantak peti belulang' (Perjanjian dengan Bintang Banyak yang sentiasa diingat menjadikan benih padi berisi seperti telah 
dilekatkan di peti besi). Bahasa kiasan metafora seperti dilekatkan di peti besi menggambarkan padi berisi lekat di tangkai. Bahasa kiasan metafora ini menggunakan unsur ciptaan manusia yakni peti besi.

\section{RUMUSAN}

Berdasarkan ungkapan maksud tersirat tersebut, kajian ini menyokong pendapat Zaitul Azma Zainon dan Ahmad Fuad Mat Hassan (2011) bahawa bahasa kiasan diungkapkan dengan bersumberkan alam semesta. Menurut teori linguistik kognitif pula, domain sumber (source domain) yang digunakan mendasari bahasa kiasan metafora dalam sampi ini terdiri daripada unsur alam dan bukan alam. Unsur alam dan bukan alam ini biasanya mempunyai hubungan yang erat dalam kalangan masyarakat Iban sehingga mereka berupaya membentuk bahasa kiasan metafora ketika melafazkan sampi. Domain sasaran (target domain) dalam kajian ini pula ialah maksud sebenar bahasa kiasan metafora iaitu warisan tradisi, merendahkan diri, persembahan sajian (piring), kehebatan perwira, kecantikan wanita dan hasil padi.

Dalam kajian Abu Hassan dan Mohd. Rasdi (2011), unsur haiwan turut digunakan untuk mengungkapkan bahasa kiasan metafora. Kajian ini mendapati terdapat dua unsur haiwan yang digunakan iaitu manuk atau ayam jantan dan ikan sungai(beluh dan enseluang). Kajian ini juga selaras dengan pandangan Asmah Haji Omar (2005) bahawa bahasa kiasan wujud melalui kemahiran manusia menilai dan melihat alam sekeliling melalui ruang yang luas dan merentasi zaman.

Kajian mendapati unsur alam dan bukan alam memainkan peranan yang besar dalam mencetuskan bahasa kiasan metafora sampi Iban. Dapatan ini menyokong teori linguistik kognitif yang melihat bahawa bahasa merupakan suatu lambang, sehingga setiap bentuk bahasa dianggap mempunyai makna serta mempunyai unsur yang membentuknya (Lakoff dan Johnson, 1980). Peranan konteks dan situasi yang diaplikasikan dalam teori sistem-fungsional turut membantu dalam proses pentafsiran makna yang dizahirkan melalui pandangan alam sekeliling dan budaya sesuatu masyarakat. Kajian turut menyokong ideologi Julian Edward (dalam Hashim Awang, 1998) bahawa masyarakat masih dipengaruhi oleh persekitaran.Pengaruh ini ditunjukkan melalui penggunaan unsur alam dan bukan alam dalam bahasa kiasan metafora sekaligus menambahkan pengetahuan pengamal tentang kemahiran berbahasa.

\section{RUJUKAN}

Abu Hassan Abdul \& Mohd. Rasdi Saamah. (2011). Unsur haiwan dalam peribahasa masyarakat asli suku kaum Semai. PENDETA - Jurnal Bahasa, Pendidikan dan Sastera Melayu, 2(1): 152-169.

Asmah Haji Omar. (2005). Budaya dan bahasa kiasan. PENDETA- Jurnal Peradaban Melayu, Vol 3 dalam penerbit.upsi.edu.my/website_e-jurnal/jurnal\%20site/.../bab1.html.

Ding, C. M. (2009). Beberapa sifat, asal usul dan kepengarangan peribahasa Melayu. Sari - International Journal of the Malay World and Civilisation. 21(2), 3-26.

Fraenkel, Jack, R. \& Wallen, Norman, E. (1993). How to design and evaluate research in education. Singapura: McGraw-Hill Inc.

Goh, S. S. (2010). Persamaan lambang dalam terjemahan peribahasa bahasa Melayu-bahasa Mandarin dalam Looi Siew Teip et al. (eds). Found in translation. Kuala Lumpur: Universiti Malaya.

Hashim Awang, A. R. (1998). Budaya dan kebudayaan: teori, isu dan persoalan. Kuala Lumpur: Citra Budaya.

Lakoff, G. \& Johnson, M. (1980). Metafore we live by. The University of Chicago Press.

Leornad, L. Jugah, Sutlive, V. H. \& Edmund, L. Saga. (2011). Bup sereba reti Jaku Iban. Tun Jugah Foundation.

Lockard, G. A. \& Saunders, G. E. (1992). Sarawak purba: Satu kajian bergambar. Pustaka Universiti Pendidkan Sultan Idris.

Mohd. Azhar Abdul Hamid. (2006). Beberapa aspek tamadun Melayu, India, Cina dan Jepun. Skudai: Universiti Teknologi Malaysia.

Phang, W. H. et al. (1983). A guide to the botanic gardens jungle. Pusat Sains Singapura. ISBN 9971-88-010-5.

Resa Sindi Harja. (2014). Bentuk dan makna peribahasa bahasa Indonesia yang terbentuk oleh unsur tumbuhan, jenis-jenis tumbuhan, dan hal-hal yang berkaitan dengan tumbuhan. Jurnal Bahtera Sastra: Antologi Bahasa dan Sastra Indonesia, 2(2).

Saleh, R. M. \& Ensiring, J. (2001). Sampi enggau biau. Kuching: Tun Jugah Foundation.

Sandai, R. (2011). A survey on problems faced by Iban language secondary school teachers. The HEAD Foundation. Routledge Critical Studies in Asean Education. 
Showren, T. (2014). Oral traditions: Method to adoptation of construction of the history of non-literate tribes. International Journal of Social Science and Humanity, Vol. 4, No. 6, 478-481.

Turner, I. M. (2010). New species of Polyalthia (Annonaceae) from Borneo and their relationship to Polyalthia cauliflora. Nordic Journal of Botany. 28, 267-279. doi: 10.1111/j.1756-1051.2009.00627.x

Zaitul. A. Z. H., \& Ahmad F. M. H. (2011). Bahasa dan pemikiran dalam peribahasa Melayu. GEMA Online Journal of Language Studies, 11(1), 31-51. 